\title{
Development of fluorescent Plasmodium falciparum for in vitro growth inhibition assays
}

\author{
Danny W Wilson 1,2, Brendan S Crabb1,2,3 and James G Beeson*1,2
}

\begin{abstract}
Background: Plasmodium falciparum in vitro growth inhibition assays are widely used to evaluate and quantify the functional activity of acquired and vaccine-induced antibodies and the anti-malarial activity of known drugs and novel compounds. However, several constraints have limited the use of these assays in large-scale population studies, vaccine trials and compound screening for drug discovery and development.

Methods: The D10 P. falciparum line was transfected to express green fluorescent protein (GFP). In vitro growth inhibition assays were performed over one or two cycles of $P$. falciparum asexual replication using inhibitory polyclonal antibodies raised in rabbits, an inhibitory monoclonal antibody, human serum samples, and anti-malarials. Parasitaemia was evaluated by microscopy and flow cytometry.

Results: Transfected parasites expressed GFP throughout all asexual stages and were clearly detectable by flow cytometry and fluorescence microscopy. Measurement of parasite growth inhibition was the same when determined by detection of GFP fluorescence or staining with ethidium bromide. There was no difference in the inhibitory activity of samples when tested against the transfected parasites compared to the parental line. The level of fluorescence of GFP-expressing parasites increased throughout the course of asexual development. Among ring-stages, GFPfluorescent parasites were readily separated from uninfected erythrocytes by flow cytometry, whereas this was less clear using ethidium bromide staining. Inhibition by serum and antibody samples was consistently higher when tested over two cycles of growth compared to one, and when using a 1 in 10 sample dilution compared to 1 in 20, but there was no difference detected when using a different starting parasitaemia to set-up growth assays. Flow cytometry based measurements of parasitaemia proved more reproducible than microscopy counts.

Conclusions: Flow cytometry based assays using GFP-fluorescent parasites proved sensitive and highly reproducible for quantifying the growth-inhibitory activity of antibodies and anti-malarials, with superior reproducibility to light microscopy, and are suitable for high-throughput applications.
\end{abstract}

\section{Background}

Malaria is a leading cause of morbidity and mortality globally and the majority of malaria-related mortality is caused by Plasmodium falciparum, particularly among children [1-3]. Antibodies are thought to be an important component of naturally acquired protective immunity against $P$. falciparum malaria. A number of studies suggest an association between antibody levels to merozoite antigens measured by enzyme linked immunosorbent assays (ELISA) and protection from malaria disease [415]. However, ELISA results are affected by the purity,

* Correspondence: beeson@wehi.edu.au

1 Infection and Immunity Division, the Walter and Eliza Hall Institute of Medical Research, 1G Royal Parade, Parkville, Victoria, 3050, Australia Full list of author information is available at the end of the article folding, and boundaries of the recombinant proteins used and cannot distinguish between functional antibodies that may contribute to protection and non-functional antibodies or blocking antibodies that could potentially interfere with the activity of protective antibodies in human samples [16-20].

Studies using rabbit polyclonal sera and monoclonal antibodies (MAb) raised by vaccination with recombinant merozoite antigens or affinity purified human antibodies suggest that antibodies against merozoite antigens are capable of interfering with merozoite invasion of the RBC directly in in vitro assays [21-27]. Plasmodium falciparum asexual stage growth inhibition assays have been used extensively in malaria research to measure the levels of growth inhibitory antibodies in clinical and pre-clinical 
studies [16,28-35]. Growth inhibition assays are also used extensively for testing the sensitivity of isolates to antimalarial drugs or screening compounds for anti-malarial activity in drug development studies.

The most readily available, simplest and most widely used method for measuring parasitaemia in growth inhibition assays is light microscopy $[29,30,33,36-40]$. However, microscopy of thin films is labour-intensive, with studies suggesting that the reproducibility of parasitaemia counts decreases with decreasing parasite density and is affected by the distribution of parasites on the slide [41,42].

High throughput approaches such as parasite lactate dehydrogenase (pLDH), and amino acid incorporation assays (hypoxanthine and isoleucine uptake assays) allow easier assessment of parasite growth for large sample sets $[17,31,32,34,35,39,43,44]$. However, since methods such as $\mathrm{pLDH}$, hypoxanthine and isoleucine uptake assays measure metabolic activity, reduced signal may be caused by inhibition of intraerythrocytic parasite development as well as inhibition of invasion $[43,45]$. Flow cytometrybased methods have been shown to be highly reproducible, scalable for efficient use in large sample sets and comparable in terms of sensitivity to alternative methods such as microscopy, hypoxanthine uptake and pLDH assays $[28,43,45-48]$.

In this study, growth inhibition assays were optimized and GFP-labelled fluorescent parasites developed and evaluated in growth inhibition assays using antibodies and anti-malarials. Furthermore, the sensitivity and reproducibility of flow cytometry for measuring parasite growth inhibition by antibodies was examined and compared to light microscopy. Previously, O'Donnell et al developed transgenic $P$. falciparum parasites expressing an antigenically distinct $19 \mathrm{kDa}$ fragment of the merozoite surface protein 1 (MSP1-19) orthologue from the rodent malaria Plasmodium chabaudi [39]; evaluating inhibition of the $P$. chabaudi MSP1-19 line versus parasites with the $P$. falciparum MSP1-19 sequence allowed measurement of $P$. falciparum MSP1-19-specific inhibitory antibodies. In this study, MSP1-19 specific growth inhibition assays were used as a model as it allowed antigen-specific inhibition to be distinguished from non-specific inhibitory activity. MSP1-19 appears to be a target of protective immunity and is an important vaccine candidate currently under development.

\section{Methods}

\section{Continuous culture of P. falciparum}

Plasmodium falciparum parasites were cultured in Petri dishes using human $\mathrm{O}^{+}$erythrocytes (RBC) maintained at $2 \%$ haematocrit [43]. Parasites were grown in RPMIHEPES culture medium ( $\mathrm{pH}$ 7.4) supplemented with 50 $\mu \mathrm{g} / \mathrm{ml}$ hypoxanthine, $25 \mathrm{mM} \mathrm{NaHCO}_{3}, 20 \mu \mathrm{g} / \mathrm{ml}$ gentam- icin, $5 \%$ (vol/vol) heat inactivated pooled human serum (various blood groups, collected by the Australian Red Cross) and 0.25\% Albumax II (Gibco, Auckland, New Zealand). In some drug inhibition experiments $0.5 \%$ Albumax was used with no human serum added. Cultures were maintained in airtight boxes at $37^{\circ} \mathrm{C}$ in an atmosphere of $1 \% \mathrm{O}_{2}, 4 \% \mathrm{CO}_{2}$ and $95 \% \mathrm{~N}_{2}$. Parasites used in these studies include the D10 clonal line, an isogenic D10-P. chabaudi MSP1-19 parasite line in which the $P$. chabaudi orthologue replaces the region of $P$. falciparum msp1 encoding MSP1-19 (known as PcMEGF), and an isogenic D10-P. falciparum MSP1-19 parasite line generated in the same manner as PcMEGF to act as a transfection control (PfM3').

\section{PfMSP1-19 specific growth inhibition assays}

The protocol for measurement of antibody inhibition of parasite growth used in this study was modified from Persson et al [43]. PfMSP1-19 and PcMSP1-19 transfected lines were maintained on $24 \mathrm{ng} / \mathrm{ml}$ pyrimethamine (to select for MSP1-19 transfectants, Sigma Aldrich, St Louis, MO, U.S.A.) with $5 \mu \mathrm{g} / \mathrm{ml}$ blasticidin-S-HCl (to select for fluorescent transfectants, Invitrogen, Carlsbad, CA, U.S.A.) added when culturing double transfected fluorescent lines. One to two cycles prior to assay set up, parasites were removed from drug selection. Mid to late trophozoite stage cultures (30-40 hours) were washed in fresh culture medium $\left(37^{\circ} \mathrm{C}\right)$, pelleted by centrifugation then diluted to $0.5 \%$ to $1 \%$ parasitaemia at $1 \%$ haematocrit for a one cycle assay, or $0.1 \%$ to $0.3 \%$ parasitaemia at $1 \%$ haematocrit for a two cycle assay. Fresh culture medium and fresh RBCs from two different donors warmed to $37^{\circ} \mathrm{C}$ were used during assay set up.

Parasitized RBCs $(25 \mu \mathrm{l}$ to $50 \mu \mathrm{l})$ at the appropriate parasitaemia were added to a 96 well U-bottom plate (Falcon, Becton-Dickinson, Franklin Lakes, NJ, U.S.A.). Inhibitory sample $(2.5 \mu \mathrm{l}$ to $5 \mu \mathrm{l}$ for a $25 \mu \mathrm{l}$ or $50 \mu \mathrm{l}$ assay respectively) was added to the parasitized RBCs giving a 1 in 10 dilution of sample in the assay (for a 1 in 20 dilution, half the volume of sample would be added). All samples were run in duplicate. A panel of non-immune sera from Melbourne donors or PBS were included as non-inhibitory controls. The 96 well plates were placed in a humidified air-tight gassed culture box at $37^{\circ} \mathrm{C}$.

One cycle ring stage assays for microscopy and flow cytometry were cultured for approximately 24 hours until young rings were visible and no schizont stage parasites remained. Thin smears of cell pellets were methanol fixed and stained with 5\% Giemsa (Merck, Darmstadt, Germany). One thousand RBCs were counted for each slide. Only early to late rings ( 0 to 20 hours old) were counted as parasitized RBCs, with each infected RBC counted as a single invasion event, regardless of how many parasites were in the cell. 
Growth assays performed over one cycle of erythrocyte invasion were cultured for 48 hours post set up until parasites were between 30-40 hours post invasion, when they were prepared for flow cytometry analysis as appropriate. Growth assays performed over two cycles of erythrocyte invasion were supplemented with $5 \mu \mathrm{l}$ to $10 \mu \mathrm{l}(25 \mu \mathrm{l}$ or 50 $\mu \mathrm{l}$ assay respectively) of fresh culture medium warmed to $37^{\circ} \mathrm{C}, 48$ hours post set up (parasites $30-40$ hours post invasion). Ninety to 96 hours post assay set up the two cycle trophozoite stage assays were prepared for flow cytometry analysis. For non-fluorescent parasite lines, RBCs were resuspended in $100 \mu \mathrm{l}$ of PBS with $10 \mu \mathrm{g} / \mathrm{ml}$ ethidium bromide (EtBr, Bio-Rad, Hercules, CA U.S.A.), stained for one hour before centrifugation, removal of the supernatant and resuspension in $200 \mu \mathrm{l}$ of PBS. GFP fluorescent parasite lines were resuspended in PBS to make a final volume of $200 \mu \mathrm{l}$. Parasitaemia was measured on a Becton Dickinson FACSCalibur (Franklin Lakes, NJ, U.S.A.) flow cytometer using a $488 \mathrm{~nm}$ laser for excitation of both GFP fluorescent (Fl-1) and EtBr stained (Fl-2) parasites. Typically, 50,000 to 80,000 RBCs were counted in each well. Samples were analysed using FlowJo software (Tree Star Inc, Ashland, OR, U.S.A.) by first gating for intact erythrocytes by side scatter and forward scatter parameters, and subsequently determining the proportion of FL1 or FL2 positive cells.

In this study, when results for both the parental PcMEGF and PfM3'lines and the GFP fluorescent PcPHG and PfPHG lines (described following) are described they will be referred to as the PcMSP1-19 and PfMSP1-19 lines, respectively. For both the PcMSP1-19 and PfMSP119 lines, parasite growth $(\mathrm{G})$ was determined by dividing the mean parasitaemia of duplicate wells for a test sample $\left(\mathrm{S}_{\text {mean }}\right)$ by the mean parasitaemia of two or more wells of non-inhibitory control $\left(\mathrm{C}_{\text {mean }}\right)$ and multiplying by $100(\mathrm{G}$ $=\left\{\mathrm{S}_{\text {mean }} / \mathrm{C}_{\text {mean }}\right\}$ *100).

Samples used in growth inhibition assays included rabbit polyclonal antibodies raised against recombinant $P$. falciparum or P. chabaudi MSP1-19 [39], an inhibitory MAb raised against 3D7 AMA1 (1F9) [49,50], the antimalarial drugs chloroquine (Sigma Aldrich, St Louis, MO U.S.A.) and quinine (Sigma Aldrich, St Louis, MO U.S.A.), serum samples from residents of Melbourne, Australia, and archived serum samples from malariaexposed adult residents of Papua New Guinea. Ethical consent for the use of human samples and blood products was obtained from the Walter and Eliza Hall Institute, and the Medical Research Advisory Council, PNG. All human samples were collected following informed consent. Serum samples were heat inactivated at $56^{\circ} \mathrm{C}$ for 45 minutes prior to use in assays.

\section{Construction of GFP plasmids for transfection}

GFP plasmids for the transfection of the PfM3' and PcMEGF MSP1-19 transfected parent lines [39,51] were modified from plasmids using Gateway ${ }^{\mathrm{m}}$ recombination technology (Invitrogen, Carlsbad, CA, U.S.A.) as described by Tonkin et al [52]. Briefly the pHGB pENTR vector [52] was digested with the restriction enzyme Xho I and gel extracted (Qiagen, Valencia, CA, U.S.A.) P. falciparum Rep20 sequence [53] was inserted 3' of the $P$. berghei DHFR terminator sequence. The resulting plasmid, pHGBr, was digested with the restriction enzymes Bgl II and Pst I and the original GFP sequence, which lacked a start codon, was replaced with a GFP mutation II sequence [54] containing a start codon to produce the plasmid pHGBr(ATG). The 5 'flanking region of the hsp86 promoter that controls GFP expression in this plasmid has been described previously [55].

The $\mathrm{pHrBl}-1 / 2$ destination vector described by Tonkin et al [52] containing the blasticidin-S-deaminase gene coding for resistance to blasticidin-S-HCl [56] was used as the destination vector in LR clonase reactions with the pHGBr(ATG) ENTR vector described above. The LR Clonase reactions were performed according to manufacturers instructions (Invitrogen, Carlsbad, CA, U.S.A.). The $\mathrm{pHrBl}-1 / 2$ destination vector $(2 \mu \mathrm{l})$ was mixed with 5 $\mu \mathrm{l}$ of the pHGBr(ATG) ENTR vector at equal concentrations (approximately $300 \mathrm{ng}$ ). Four microlitres of $5 \times \mathrm{LR}$ Clonase reaction buffer and $4 \mu \mathrm{l}$ of LR Clonase enzyme mix were added (Invitrogen, Carlsbad, CA, U.S.A.). The reaction mixture was made up to $20 \mu \mathrm{l}$ with TE Buffer $(\mathrm{pH} 8.0)$ and the reaction allowed to proceed for 1 hour at room temperature. The reaction was stopped by the addition of proteinase K (Roche Diagnostics, Mannheim, Germany) and incubation at $37^{\circ} \mathrm{C}$ for 10 minutes. The LR clonase reactions were then transformed directly into $\mathrm{CcdB}$ sensitive electrocompetent bacterial cells. The presence of the pHGBrHrBl-1/2 vector (Figure 1) in bacterial clones was confirmed by restriction digest. Plasmids for transfection were purified from $500 \mu \mathrm{l}$ of bacterial culture using a Plasmid Maxi kit (Qiagen, Valencia, CA, U.S.A.) according to manufacturers instructions.

\section{Transfection of parasites with fluorescence plasmids}

Transfection of $P$. falciparum parasites PfM3' and PcMEGF with the pHGBrHrBl-1/2 plasmid was undertaken as described previously [57] using modified electroporation conditions [58]. Briefly, approximately $70 \mu \mathrm{g}$ of purified plasmid DNA was resuspended in $15 \mu \mathrm{l}$ of warm TE buffer. Three hundred and eighty five microlitres of sterile, warm $\left(37^{\circ} \mathrm{C}\right)$ cytomix $(120 \mathrm{mM} \mathrm{KCl}$, $0.15 \mathrm{mM} \mathrm{CaCl}, 2 \mathrm{mM}$ EGTA, $5 \mathrm{mM} \mathrm{MgCl}_{2}, 10 \mathrm{mM}$ $\mathrm{K}_{2} \mathrm{HPO}_{4} / \mathrm{KH}_{2} \mathrm{PO}_{4} \mathrm{pH}$ 7.6, 25 mM HEPES $\mathrm{pH}$ 7.6) were added to the plasmid and then mixed with $200 \mu \mathrm{l}$ of infected RBC with 5-8\% ring stage parasites before being transferred to a $0.2 \mathrm{~cm}$ electroporation cuvette. The cytomix and infected RBC mix was electroporated at $950 \mu \mathrm{F}$ capacitance and $0.31 \mathrm{kV}$ (Biorad Gene Pulser II, Biorad, Hercules, CA, U.S.A.) and the infected red blood cells 


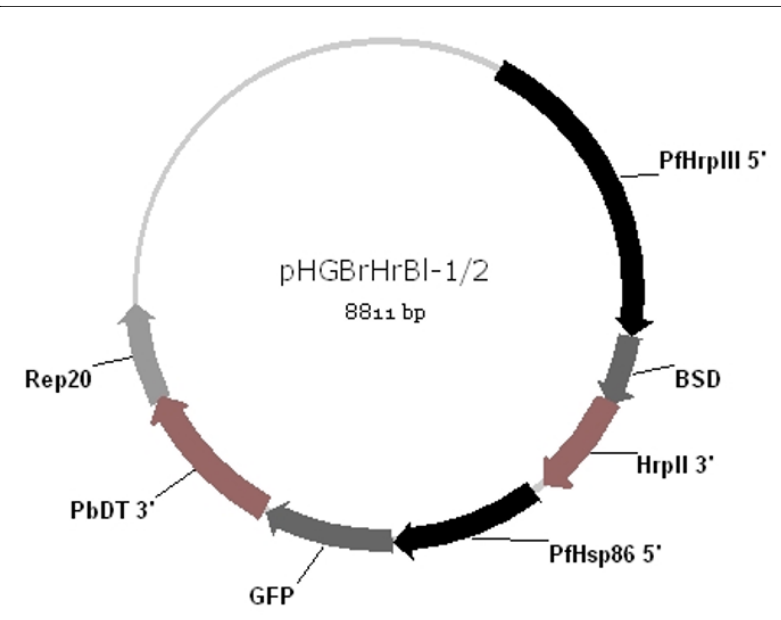

Figure 1 Green fluorescent protein (GFP) transfection plasmid. Plasmid $\mathrm{pHGBrHrBl-1/2}$ was constructed and used to transfect $P$. falciparum blood-stage parasites in vitro. Letters and numbers forming the name of the plasmid are in bold. The plasmid has the $\mathbf{H s p 8 6} 5^{\prime}$ promoter driving GFP expression with a P. berghei 3 ' terminator region (B), and rep20 targeting sequence. The drug cassette contains the PfHrpllI 5' promoter driving blasticidin-S-deaminase (BSD) (BI) with a PfHrpll 3' terminator. Fluorescence and drug cassettes are orientated in a head to tail orientation (5' to $3^{\prime}$ end followed by $5^{\prime}$ to $3^{\prime}$ end) $(\mathbf{1 / 2}$ ).

transferred immediately into $10 \mathrm{ml}$ of culture medium containing $2 \%$ haematocrit RBCs, placed into a airtight gassed chamber and incubated at $37^{\circ} \mathrm{C}$.

Drug cycling commenced two days after transfection using $5 \mu \mathrm{g} / \mathrm{ml}$ of blasticidin-S- $\mathrm{HCl}$ to select for fluorescent parasites with $24 \mathrm{ng} / \mathrm{ml}$ of pyrimethamine added to maintain integration of the MSP1-19 transfection vectors. After the second cycle of drug selection, fluorescent parasites expressing GFP were cloned by limiting dilution for use in experiments. In order to ensure maintainance of both the MSP1-19 and GFP transfection plasmids for experiments, cloned parasites were cultured with the appropriate drugs (pyrimethamine and blasticidin-S$\mathrm{HCl}$, respectively). Typically, there was no evidence for the loss of GFP fluorescence or expression of the $P$. chabaudi MSP1-19 phenotype with up to two months of continuos culture. To explore whether other isolates could be successfully transfected with the same plasmid, isolates CS2 and E8B, derived from the ITG line, were also transfected.

Successful transfection of parasites with GFP plasmids was confirmed by live parasite fluorescence microscopy using an upright Zeiss Axioskop fluorescence microscope (Carl Zeiss, Jena, Germany) with parasite nuclei stained with $0.5 \mu \mathrm{g} / \mathrm{ml}$ DAPI (Sigma Aldrich, St Louis, MO, U.S.A.). For flow cytometry GFP fluorescent lines were stained with $\mathrm{EtBr}$ and the number of fluorescent parasites were quantified using a FACSCalibur and analysed using FlowJo software.

\section{Results}

Inhibitory polyclonal and monoclonal antibodies

Polyclonal rabbit antibodies raised against PfMSP1-19 and PcMSP1-19 and a MAb raised against 3D7 AMA1 $[49,50]$ were tested against PfMSP1-19 and PcMSP1-19 lines for growth-inhibitory activity; the PcMSP1-19 line contains the orthologous $P$. chabaudi MSP1-19 sequence in place of the endogenous $P$. falciparum sequence [39]. The PfMSP1-19 rabbit antiserum was found to specifically inhibit growth of the PfMSP1-19 line. PcMSP1-19 specific rabbit antiserum and purified IgG specifically inhibited growth of the PcMSP1-19 line. The AMA1 MAb which recognizes a region of $P$. falciparum AMA1 domain 1 common to both the 3D7 and D10 parasite lines showed similar levels of growth inhibition of the PfMSP1-19 and PcMSP1-19 lines at a concentration of $0.5 \mathrm{mg} / \mathrm{ml}$. The reproducibility of PfMSP1-19 specific rabbit antibodies in growth inhibition assays was confirmed in repeat experiments throughout the course of this study in both one cycle and two cycle assays (Figure 2).

\section{Optimisation of flow cytometry based growth assays}

Prior studies using transgenic parasites to measure MSP1-19 specific inhibitory antibodies have been largely performed using microscopy-based assays, rather than by flow-cytometry, and there are limited data on conditions that influence growth-inhibition assay results or on assay reproducibility. Therefore, studies were performed to optimize flow cytometry-based growth inhibition assays. Different assay start parasitaemias were examined in order to determine the optimal conditions for measuring parasite growth inhibition. PfMSP1-19 parasite growth over one cycle in the presence of rabbit antisera or malaria exposed human samples showed a strong correlation between experiments using a starting parasitaemia of $0.5 \%$ and $1 \%(\mathrm{r}=0.95, \mathrm{n}=13, \mathrm{p}<0.0001)$. Two cycle assays set up at $0.05 \%, 0.1 \%$ and $0.3 \%$ parasitaemia showed a strong correlation between PfMSP1-19 growth for the $0.05 \%$ and $0.1 \%$ assays $(\mathrm{r}=0.95, \mathrm{n}=13, \mathrm{p}<0.0001)$ and the $0.1 \%$ and $0.3 \%$ assays $(\mathrm{r}=0.98, \mathrm{n}=8, \mathrm{p}<0.0001)$. These data suggest the start parasitaemia was unlikely to influence the sensitivity of parasite growth inhibition assays over the range of starting parasitaemia tested.

MSP1-19 specific rabbit antisera and the AMA1 MAb were compared in one cycle and two cycle growth inhibition assays to determine whether a second cycle of parasite growth would increase the sensitivity of the assay. Growth of the PcMSP1-19 parasite line in the presence of inhibitory antibodies showed that a second cycle increased antibody mediated growth inhibition for both the PcMSP1-19 and AMA1 antibodies but not the PfMSP1-19 antibodies (Figure 3A). Similarly, growth of the PfMSP1-19 line was considerably lower after two 


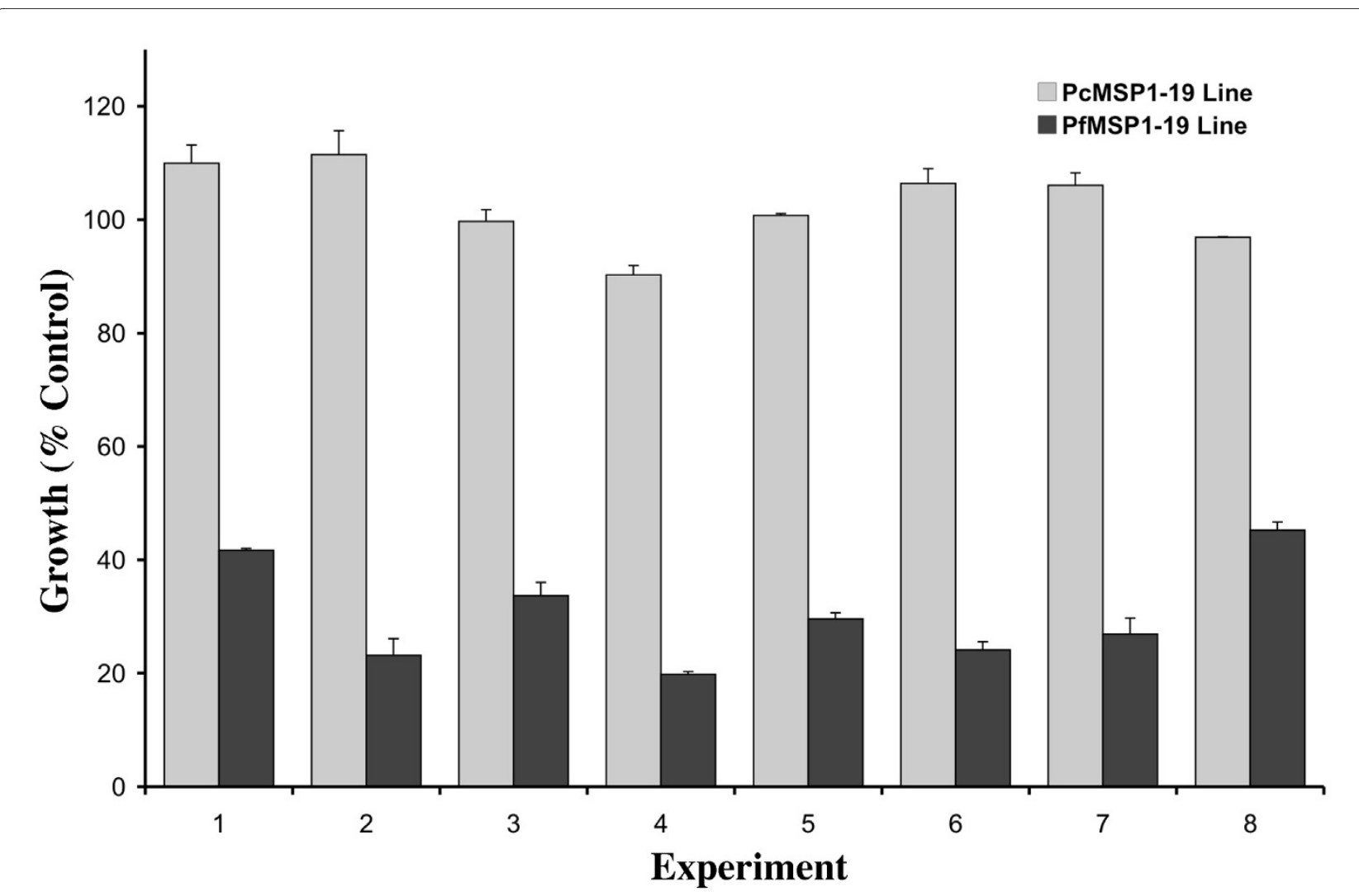

Figure 2 Specificity and reproducibility of growth inhibition by PfMSP1-19 specific antibodies. PfMSP1-19 specific inhibitory rabbit antiserum was added at a 1 in 10 dilution in two cycle growth assays. Growth is expressed as a percentage of controls (sera from non-exposed Australian residents). Results are from 8 different experiments carried out between December 2005 and July 2007. Assays were performed in duplicate and values represent the mean + range.

cycles in the presence of the PfMSP1-19 and AMA1 specific antibodies but not the PcMSP1-19 antibodies (Figure 3B). These data suggest that a second cycle of parasite growth increases growth inhibition due to antibodies compared to one cycle assays. Inhibition by MSP1-19 specific antibodies over two cycles of parasite replication was approximately double that observed in one cycle assays.

A number of published studies comparing growth of the PcMSP1-19 line and the PfMSP1-19 line have used a 1 in 20 volume of sample in one cycle microscopy based assays [36-39]. For the purposes of this study, an assay set up modified from Perrson et al [43] using a 1 in 10 sample dilution was compared to a 1 in 20 sample dilution in one cycle flow cytometry based assays with MSP1-19 specific rabbit antisera. Growth of the PcMSP1-19 transfected line when PcMSP1-19 antisera was added was higher for the 1 in 20 dilution assay than the 1 in 10 dilution assay (Figure 3C). Similarly PfMSP1-19 line growth in the presence of PfMSP1-19 antisera at a 1 in 20 dilution was higher than at a 1 in 10 dilution (Figure 3D). The specificity of the MSP1-19 rabbit antisera was confirmed by the absence of a dose-response inhibitory effect on the control MSP1-19 line for PfMSP1-19 or PcMSP1-19 antibodies (i.e. PfMSP1-19 antibodies did not substantially inhibit the PcMSP1-19 line, or vice-versa). Similarly, median growth of the PfMSP1-19 transfected parasite line in a 1 in 10 dilution experiment for a panel of malaria exposed non-dialysed adult samples $(\mathrm{n}=15)$ was lower (growth 59.2\%) compared to the median growth for 1 in 20 dilution experiments (growth $85.6 \%$ ) relative to control in one cycle experiments indicating an inhibitory dose response effect of human samples on parasite growth.

\section{Transfection of MSP1-19 chimeric lines with green fluorescent protein (GFP)}

The PfM3' and PcMEGF MSP1-19 lines developed by O'Donnell et al $[39,51]$ were transfected with a plasmid expressing GFP under Blasticidin $\mathrm{HCl}$ drug selection (transfection of PfM3' leading to PfPHG, transfection of PcMEGF leading to PcPHG). Fluorescence microscopy indicated that GFP fluorescence was not targeted to specific organelles but instead coloured the whole parasite 

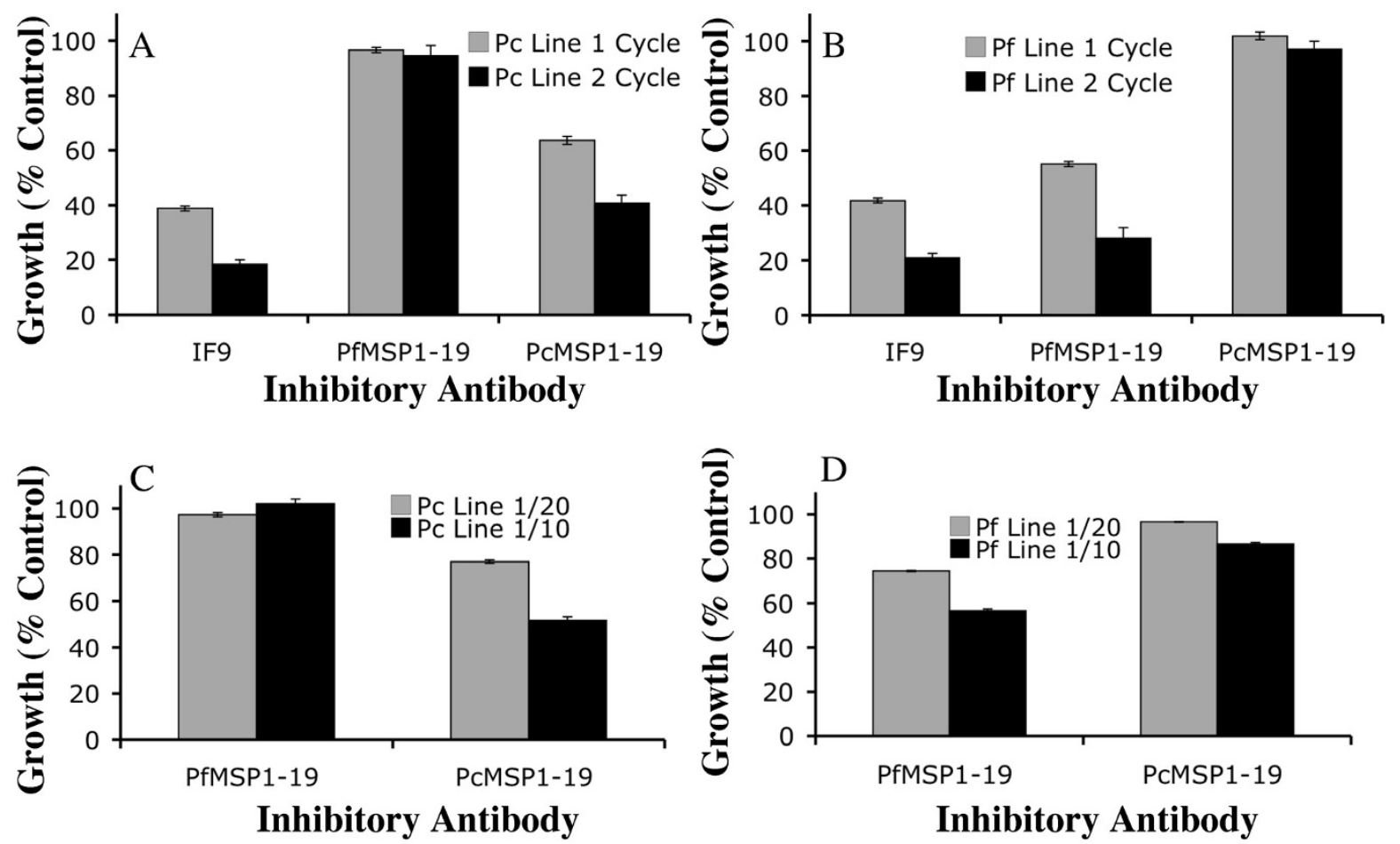

Figure 3 Optimisation of growth inhibition assays. Comparison of one and two cycle parasite growth inhibition assays using the 3D7 AMA1 (1F9) monoclonal antibody (0.5 mg/ml), PfMSP1-19 rabbit antiserum (1 in 10 dilution) and PcMSP1-19 rabbit antiserum (1 in 10 dilution) for (A) the PcMSP119 parasite line and (B) the PfMSP1-19 parasite line. Comparison of parasite growth inhibition by samples tested at either 1 in 10 or 1 in 20 dilution in a one cycle growth assay for (C) the PCMSP1-19 and (D) the PfMSP1-19 parasite lines. Growth is expressed as a percentage of controls (sera from nonexposed Australian residents). The mean of duplicate or multiple values is shown and error bars represent the range when tested in duplicate or standard error of the mean for 4 or more values as appropriate.

cytoplasm (Figure 4A). GFP fluorescent parasites were detectable in all asexual stages of the life cycle.

The fluorescence profile of both $\mathrm{EtBr}$ stained and unstained PfPHG GFP expressing parasites was examined during the course of the asexual parasite lifecycle. GFP fluorescence profiles for early ring stage parasites (2, 6-10, 14-18 hours post invasion) separated clearly from the uninfected RBC population (Figure 4B,D). This allowed the parasitaemia of GFP fluorescent parasites to be measured by flow cytometry at any stage of the parasite life cycle, including early rings. As the parasites matured, the mean fluorescence intensity (MFI) of GFP positive parasites increased. There was a consistent increase in MFI associated with time post invasion (Figure 4B). GFP fluorescence was not influenced by whether or not the parasites had been stained with EtBr. EtBr stained parasite fluorescence peaked around 36-40 hours post invasion, with a noticeable increase in mean fluorescence intensity from approximately 22-26 hours to 36-40 hours post invasion (Figure 4C). Early ring stage parasites (0-12 hours post invasion) stained with $\mathrm{EtBr}$ generally separated poorly from the RBC population (Figure 4E).
Although the vector was designed to transfect the D10 PcMEGF and PfM3' lines, the same vector was successfully used to transfect other parasite lines, CS2 and E8B; fluorescence was confirmed by flow cytometry and immunofluorescence microscopy. Other vectors could be generated for specific applications.

\section{Validation of GFP fluorescent parasites in growth assays using inhibitory antibodies and anti-malarial drugs}

There was a strong correlation between GFP fluorescence and EtBr staining for measurements of PfPHG parasite growth in two cycle assays $(\mathrm{r}=0.97, \mathrm{n}=57, \mathrm{p}<0.0001)$ in the presence of inhibitory and non-inhibitory samples. Growth of the PfPHG GFP expressing line also correlated strongly with growth of the PfM3' parent line in inhibitory and non-inhibitory samples for two cycle assays $(\mathrm{r}=$ $0.88, \mathrm{n}=27, \mathrm{p}<0.0001$ ).

Inhibition of parasite growth by antibodies for the PcPHG and PfPHG fluorescent lines was compared to inhibition of the PcMEGF and the PfM3' parent lines in two cycle assays. Growth of the PcPHG GFP expressing line was found to be the same as the PcMEGF non-GFP 


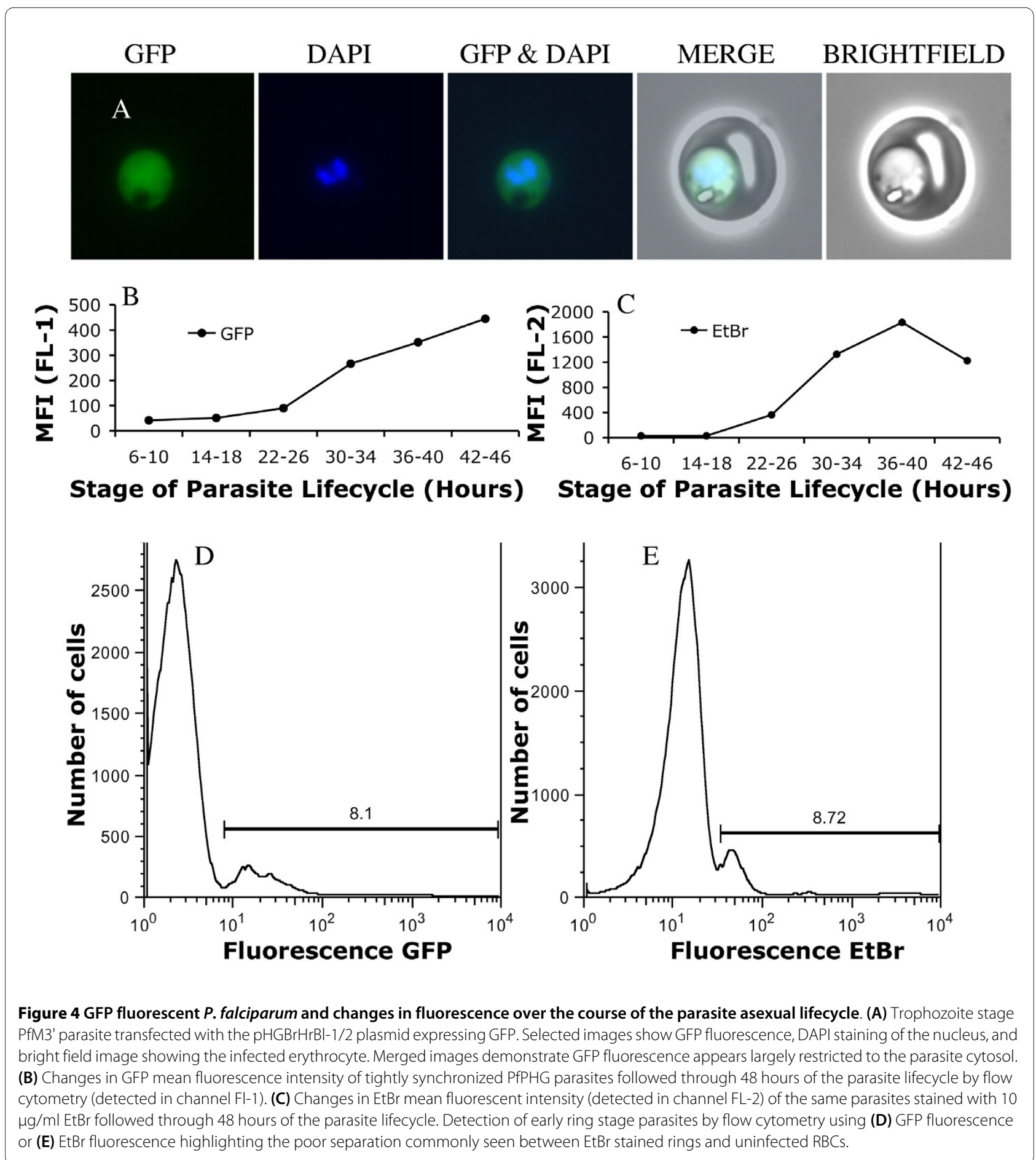

parent line in the presence of $P$. chabaudi MSP1-19 specific antiserum, P. falciparum MSP1-19 specific antiserum (Figure 5A) and AMA1 MAb. Similarly, growth of the PfPHG GFP expressing line and the PfM3' non-GFP parent line was found to be the same in the presence of $P$. chabaudi MSP1-19 specific antiserum, P. falciparum MSP1-19 specific antiserum (Figure 5B) and AMA1 $\mathrm{MAb}$, as expected. The level of inhibition between the parent and GFP transfected lines in the presence of MSP1-19 specific rabbit antisera was reproducible over multiple assays.

The utility of GFP-fluorescent lines in growth assays was also evaluated with anti-malarial drugs. The growth of PfPHG parasites in the presence of the anti-malarial drugs chloroquine (Figure 5C) and quinine (Figure 5D) showed a strong correlation between measurements 


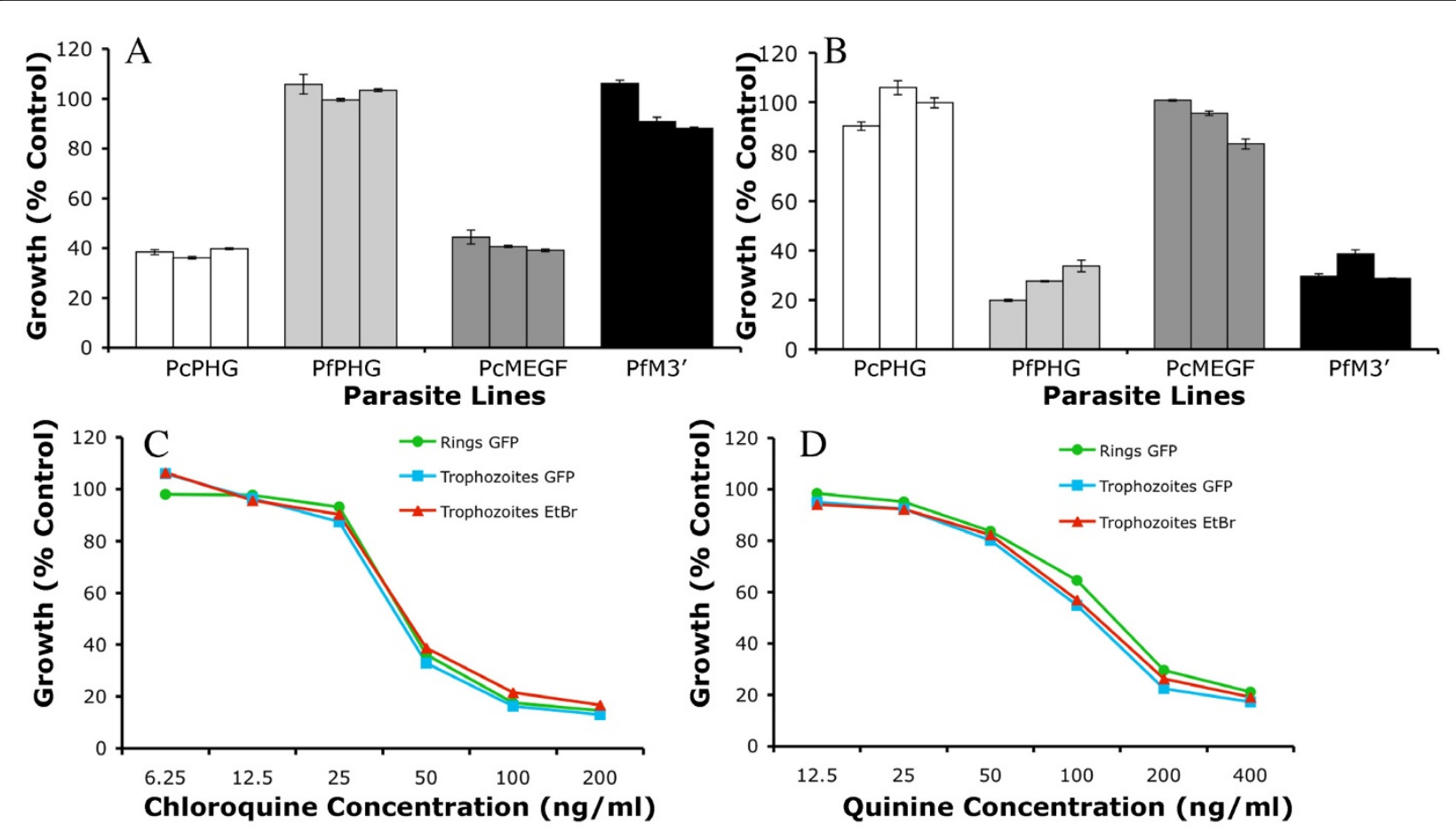

Figure 5 Measurement of growth inhibitory activity of antibodies and anti-malarial drugs using GFP fluorescent parasites. Comparison between the GFP transfected PCPHG and PfPHG lines and the parental parasites (PCMEGF and PfM3', respectively) of growth-inhibitory activity of (A) PCMSP1-19 specific rabbit antisera and (B) PfMSP1-19 specific rabbit antisera. Results represent data from three independent two cycle growth assays with samples tested at 1 in 10 dilution. Growth is expressed as a percentage of controls (sera from non-exposed Australian residents) and values represent means with SEM. Inhibition of the PfPHG parasite line by (C) chloroquine and (D) quinine in a one cycle growth assay. Parasitaemia was measured by flow cytometry using ring stage GFP fluorescence, late trophozoite stage GFP fluorescence or late trophozoite stage EtBr fluorescence.

Growth is expressed as a percentage of PBS control.

made at ring stage (based on GFP fluorescence) and mature trophozoite stage detected by GFP fluorescence or EtBr fluorescence. The correlation between parasitaemia measured by GFP and EtBr in the presence of chloroquine and quinine indicated that the two methods were equally sensitive. There was no evidence that either method was significantly overstating parasitaemia due to increased background reading.

Taken together, these data suggest that expression of GFP does not alter parasite susceptibility to inhibitory antibodies or anti-malarial drugs. GFP fluorescent parasites are potentially a useful tool for measurement of parasite growth inhibition in in vitro assays.

\section{Measurement of parasitaemia by microscopy versus flow cytometry}

Further studies were performed to evaluate flow-cytometry-based measurements of parasitaemia compared to microscopy. In total, 55 samples, including inhibitory antibodies and serum samples from malaria-exposed and non-exposed donors were compared between microscopy and flow cytometry based measurements of parasite growth for duplicate wells across three experiments.
Counts for 15 samples by a second microscopist were available for comparison. There was noticeable variation in measurements by microscopy between duplicate wells for both the PcMSP1-19 line (correlation between wells $r$ $=0.76, \mathrm{n}=70, \mathrm{p}<0.0001$, mean difference in parasitaemia between duplicate wells $0.8 \%$, range $0 \%$ to $5.5 \%$ ) and the PfMSP1-19 line $(\mathrm{r}=0.80, \mathrm{n}=70, \mathrm{p}<0.0001$, mean difference in parasitaemia between duplicate wells $0.7 \%$, range $0 \%$ to $2.8 \%$, Figure $6 \mathrm{~A}$ ). In contrast, for flow cytometry based assays, there was a very strong correlation between measurements of parasitaemia for duplicate wells for both the PcMSP1-19 $(\mathrm{r}=0.99, \mathrm{n}=55, \mathrm{p}<0.0001$, mean difference in parasitaemia between duplicate wells $0.1 \%$, range $0 \%$ to $0.3 \%)$ and PfMSP1-19 $(\mathrm{r}=0.98, \mathrm{n}=55$, $\mathrm{p}<0.0001$, mean difference in parasitaemia between duplicate wells $0.1 \%$, range $0 \%$ to $0.7 \%$, Figure $6 \mathrm{~B}$ ) lines.

The reproducibility of parasitaemia measurements was examined for a single experiment where counts for duplicate wells were available for two microscopists (M1 and M2) and a flow cytometry based assay. Measurements of parasitaemia between duplicate wells were compared for all samples and control treatments $(n=13)$ in the experiment for both the PcMEGF and PfM3' parasite lines. The 

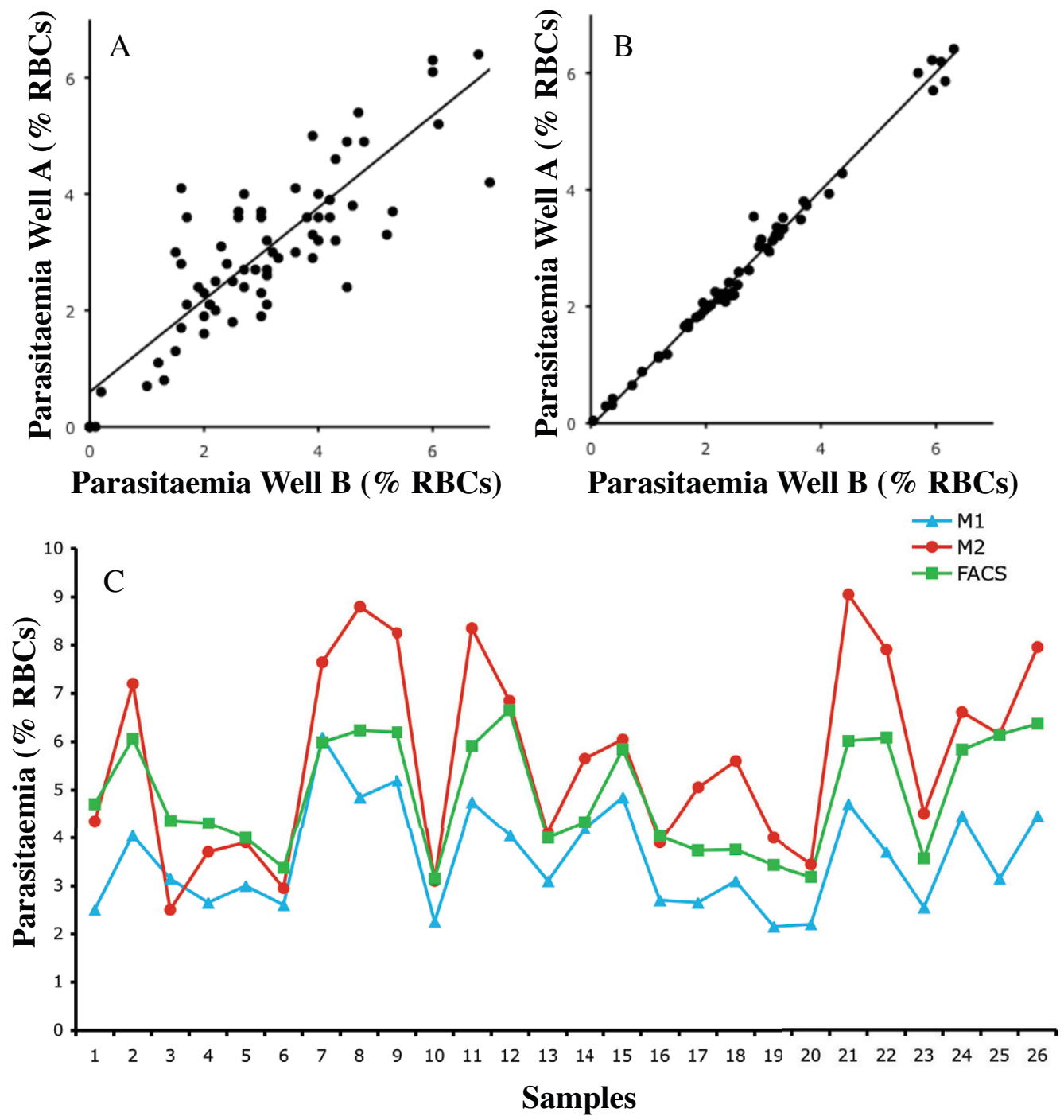

Figure 6 Measurement of parasite growth inhibition by microscopy and flow cytometry. Correlation between duplicate wells of parasitaemia counts from a growth inhibition assay using (A) ring stage microscopy $(n=70)$ or (B) flow cytometry $(n=55)$. The higher number of samples available for ring stage microscopy reflects the availability of counts from a second microscopist. The PfMSP1-19 line was used in this comparison and tested for inhibition by rabbit anti-MSP1-19 antibodies and a selection of samples from malaria-exposed and non-exposed donors. (C) Mean parasitaemia counts for duplicate wells determined by ring stage microscopy counts for microscopist one (M1) and microscopist two (M2) compared to parasitaemia measured by flow cytometry (trophozoite stage parasites) using the PCMSP1-19 and PfMSP1-19 lines. Samples used were serum from malaria exposed individuals and unexposed controls numbered 1-26 for ease of comparison.

mean percentage difference in parasitaemia counts between duplicates wells for all treatments and both lines in the flow cytometry based assay was $0.2 \%$ (range $0 \%$ to $0.7 \%$ ). The mean percentage difference between duplicate wells across all serum treatments for M1 was $0.6 \%$ (range
$0 \%$ to $1.6 \%$ ). For $\mathrm{M} 2$ the mean percentage difference between duplicate wells across all serum treatments was $1.5 \%$ (range $0 \%$ to $5.5 \%$ ).

Comparison between microscopist M1, microscopist M2 and flow cytometry based counts of parasitaemia 
(mean of duplicate wells) suggested that the counts for M1 (mean of all samples 3.6\%) tended to underestimate parasitaemia relative to flow cytometry counts (mean 4.9\%), while the counts of M2 (mean 5.7\%) tended to overestimate parasitaemia relative to flow cytometry (Figure 6C). The comparison also highlights where parasitaemia counts from both microscopists differed widely to that of the flow cytometry parasitaemia counts for individual samples.

\section{Discussion}

In this study, flow cytometry-based growth inhibition assays [43] were further evaluated and optimized and GFP-fluorescent lines were developed and validated for use in measuring growth-inhibitory antibodies and the activity of anti-malarial agents. Inhibition of parasite growth in the presence of MSP1-19 specific rabbit antisera [39], AMA1 MAb [49,50] and human samples from malaria-exposed individuals was higher in two cycle assays than in one cycle assays, as previously reported [43]. Similarly, MSP1-19 specific rabbit antisera and human samples were more inhibitory at a 1 in 10 dilution than a 1 in 20 dilution. Assay starting parasitaemia did not appear to affect the level of parasite growth inhibition for inhibitory samples. There was a strong correlation between duplicate wells and repeat experiments for both one cycle and two cycle flow cytometry based assays as reported previously [43,48]. Importantly, the level of inhibition for all three inhibitory antibodies was found to be highly reproducible throughout the course of the study for both one cycle and two cycle assays.

GFP fluorescent PcMSP1-19 and PfMSP1-19 parasites were developed to reduce handling and improve sensitivity in flow cytometry based growth assays; parasites were transfected to express GFP under control of the HSP-86 promoter on both the PcMEGF (PcPHG) and PfM3' (PfPHG) parent line backgrounds and parasites were cloned for subsequent use. Parasites expressing cytoplasmic GFP were easily detectable by flow cytometry and measurements of parasitaemia correlated strongly between GFP fluorescent parasites and parasites detected using the established method of staining with ethidium bromide.

There are several advantages of using GFP-fluorescence compared to nucleic acid dyes to detect parasitaemia. The use of the GFP fluorescent parasites removed the need to use a nucleic acid stain for parasite detection by flow cytometry, thereby reducing handling, and gave better resolution between ring stage parasites and uninfected RBCs by flow cytometry compared to EtBr stained rings. Furthermore, fluorescent parasites can be sorted using flow cytometry and used in down-stream applications that require live viable parasites, which can be problematic with nucleic acid dyes [59,60]. Detection of GFP fluorescent parasites was found to be as reliable as detection using EtBr stain in flow cytometry based growth assays, with strong correlations between measured parasitaemia for both one cycle and two cycle growth assays. Growth of GFP transfected and parental parasites was found to be comparable in the presence of MSP1-19 specific inhibitory rabbit antisera, inhibitory AMA1 MAb and malaria exposed human samples. This suggests that parasites expressing GFP are a valid and reliable alternative to the use of a nucleic acid stain such as EtBr for counting parasitaemia by flow cytometry in in vitro assays. These studies demonstrate that GFP-fluorescent parasites could be used in assays to measure acquired immunity or vaccine-induced responses in the development and testing of blood-stage vaccines, or for screening and evaluation of compounds with anti-malarial activity.

Finally, the measurement of parasitaemia by flow cytometry was found to be more accurate and reproducible than microscopy. Reproducibility of parasitaemia counts between duplicate wells was much higher for flow cytometry than microscopy. Differences in parasitaemia counts between duplicate wells of the same sample were as high as $98 \%$ by microscopy, whereas parasitaemia counts by flow cytometry were very similar for duplicate wells of the same sample, suggesting that much of the variation between duplicate wells in microscopy is caused by observer error. There was also substantial variability in results between microscopists.

\section{Conclusions}

The development and optimisation of flow cytometry based growth inhibition assays using parasite lines transfected to express GFP resulted in a highly reproducible assay that was sensitive and suitable for measuring the inhibitory activity of antibodies and anti-malarial agents. Results were highly reproducible between experiments, between duplicate samples and superior to microscopy.

\section{Competing interests}

The authors declare that they have no competing interests.

\section{Authors' contributions}

DWW - study design, analysis and interpretation of results, performed experiments, wrote the manuscript with JGB; BSC - study design, interpretation of results and contributed to writing the manuscript; JGB - study design, analysis and interpretation of results, wrote the manuscript with DWW. All authors read and approved the final manuscript.

\section{Acknowledgements}

The authors would like to thank Chris Tonkin (The Walter and Eliza Hall Institute) and Giel van Dooren (Department of Biochemistry, University of Melbourne) for provision of plasmids and advice during construction of GFP transfection plasmids, Paul Gilson (Burnet Institute) for advice and technica assistance throughout the study, Salenna Elliott for help with preparing the manuscript, and Robin Anders and Mick Foley (LaTrobe University) for the use of 1F9 AMA1 MAb. Erythrocytes and serum for parasite culture were kindly provided by the Red Cross Blood Bank (Melbourne). Funding was provided by the National Health and Medical Research Council of Australia (Project grant and Career Development Award to J. Beeson; Program grant to B. Crabb; Postgrad- 
uate Research Fellowship to D. Wilson; Independent Research Institutes Infrastructure Support Scheme Grant to the Walter and Eliza Hall Institute), the Victorian State Government (Operational Infrastructure Support Grant to the Walter and Eliza Hall Institute), and the Miller Fellowship of the Walter and Eliza Hall Institute (to J. Beeson)

\section{Author Details}

IInfection and Immunity Division, the Walter and Eliza Hall Institute of Medical Research, 1G Royal Parade, Parkville, Victoria, 3050, Australia, 2Department of Medical Biology, University of Melbourne, Victoria, Australia and ${ }^{3}$ Macfarlane Burnet Institute for Medical Research and Public Health, Melbourne, Victoria 3004, Australia

Received: 21 December 2009 Accepted: 3 June 2010

Published: 3 June 2010

\section{References}

1. WHO: Malaria, 1982-1997. Wkly Epidemiol Rec 1999, 74:265-270.

2. Elliott SR, Beeson JG: Estimating the burden of global mortality in children aged $<5$ years by pathogen-specific causes. Clin Infect Dis 2008, 46:1794-1795.

3. Snow RW, Guerra CA, Noor AM, Myint HY, Hay Sl: The global distribution of clinical episodes of Plasmodium falciparum malaria. Nature 2005, 434:214-217.

4. Osier FH, Fegan G, Polley SD, Murungi L, Verra F, Tetteh KK, Lowe B, Mwangi T, Bull PC, Thomas AW, Cavanagh DR, McBride JS, Lanar DE, Mackinnon MJ, Conway DJ, Marsh K: Breadth and magnitude of antibody responses to multiple Plasmodium falciparum merozoite antigens are associated with protection from clinical malaria. Infect Immun 2008, 76:2240-2248

5. Nebie I, Diarra A, Ouedraogo A, Soulama I, Bougouma EC, Tiono AB, Konate AT, Chilengi R, Theisen M, Dodoo D, Remarque E, Bosomprah S, Milligan P, Sirima SB: Humoral responses to Plasmodium falciparum blood-stage antigens and association with incidence of clinical malaria in children living in an area of seasonal malaria transmission in Burkina Faso, West Africa. Infect Immun 2008, 76:759-766.

6. Roussilhon C, Oeuvray C, Muller-Graf C, Tall A, Rogier C, Trape JF, Theisen $M$, Balde A, Perignon JL, Druilhe P: Long-term clinical protection from falciparum malaria is strongly associated with $\operatorname{lgG} 3$ antibodies to merozoite surface protein 3. PLoS Med 2007, 4:e320

7. Osier FH, Polley SD, Mwangi T, Lowe B, Conway DJ, Marsh K: Naturally acquired antibodies to polymorphic and conserved epitopes of Plasmodium falciparum merozoite surface protein 3. Parasite Immunol 2007, 29:387-394.

8. Polley SD, Conway DJ, Cavanagh DR, McBride JS, Lowe BS, Williams TN, Mwangi TW, Marsh K: High levels of serum antibodies to merozoite surface protein 2 of Plasmodium falciparum are associated with reduced risk of clinical malaria in coastal Kenya. Vaccine 2006, 24:4233-4246.

9. Soe S, Theisen M, Roussilhon C, Aye KS, Druilhe P: Association between protection against clinical malaria and antibodies to merozoite surface antigens in an area of hyperendemicity in Myanmar: complementarity between responses to merozoite surface protein 3 and the 220kilodalton glutamate-rich protein. Infect Immun 2004, 72:247-252.

10. Polley SD, Mwangi T, Kocken CH, Thomas AW, Dutta S, Lanar DE, Remarque E, Ross A, Williams TN, Mwambingu G, Lowe B, Conway DJ, Marsh K: Human antibodies to recombinant protein constructs of Plasmodium falciparum Apical Membrane Antigen 1 (AMA1) and their associations with protection from malaria. Vaccine 2004, 23:718-728.

11. Metzger WG, Okenu DM, Cavanagh DR, Robinson JV, Bojang KA, Weiss HA, McBride JS, Greenwood BM, Conway DJ: Serum IgG3 to the Plasmodium falciparum merozoite surface protein 2 is strongly associated with a reduced prospective risk of malaria. Parasite Immunol 2003, 25:307-312.

12. Oeuvray C, Theisen M, Rogier C, Trape JF, Jepsen S, Druilhe P: Cytophilic immunoglobulin responses to Plasmodium falciparum glutamate-rich protein are correlated with protection against clinical malaria in Dielmo, Senegal. Infect Immun 2000, 68:2617-2620.

13. Migot-Nabias F, Luty AJ, Ringwald P, Vaillant M, Dubois B, Renaut A, Mayombo RJ, Minh TN, Fievet N, Mbessi JR, Millet P, Deloron P: Immune responses against Plasmodium falciparum asexual blood-stage antigens and disease susceptibility in Gabonese and Cameroonian children. Am J Trop Med Hyg 1999, 61:488-494.
14. Alifrangis M, Lemnge MM, Moon R, Theisen M, Bygbjerg I, Ridley RG, Jakobsen PH: IgG reactivities against recombinant Rhoptry-Associated Protein-1 (rRAP-1) are associated with mixed Plasmodium infections and protection against disease in Tanzanian children. Parasitology 1999, 119:337-342.

15. Taylor RR, Allen SJ, Greenwood BM, Riley EM: IgG3 antibodies to Plasmodium falciparum merozoite surface protein 2 (MSP2): increasing prevalence with age and association with clinical immunity to malaria. Am J Trop Med Hyg 1998, 58:406-413.

16. McCallum FJ, Persson KE, Mugyenyi CK, Fowkes FJ, Simpson JA, Richards JS, Williams TN, Marsh K, Beeson JG: Acquisition of growth-inhibitory antibodies against blood-stage Plasmodium falciparum. PLOS ONE 2008, 3:e3571

17. Miura K, Zhou H, Moretz SE, Diouf A, Thera MA, Dolo A, Doumbo O, Malkin E, Diemert D, Miller LH, Mullen GE, Long CA: Comparison of biological activity of human anti-apical membrane antigen-1 antibodies induced by natural infection and vaccination. J Immuno/ 2008, 181:8776-8783.

18. Nwuba RI, Sodeinde O, Anumudu Cl, Omosun YO, Odaibo AB, Holder AA, Nwagwu M: The human immune response to Plasmodium falciparum includes both antibodies that inhibit merozoite surface protein 1 secondary processing and blocking antibodies. Infect Immun 2002, 70:5328-5331

19. Egan AF, Burghaus P, Druilhe P, Holder AA, Riley EM: Human antibodies to the $19 \mathrm{kDa}$ C-terminal fragment of Plasmodium falciparum merozoite surface protein 1 inhibit parasite growth in vitro. Parasite Immunol 1999, 21:133-139.

20. Guevara Patino JA, Holder AA, McBride JS, Blackman MJ: Antibodies that inhibit malaria merozoite surface protein-1 processing and erythrocyte invasion are blocked by naturally acquired human antibodies. J Exp Med 1997, 186:1689-1699.

21. Hodder AN, Crewther PE, Anders RF: Specificity of the protective antibody response to apical membrane antigen 1. Infect Immun 2001, 69:3286-3294

22. Mitchell GH, Thomas AW, Margos G, Dluzewski AR, Bannister LH: Apical membrane antigen 1 , a major malaria vaccine candidate, mediates the close attachment of invasive merozoites to host red blood cells. Infect Immun 2004, 72:154-158.

23. Dutta S, Haynes JD, Moch JK, Barbosa A, Lanar DE: Invasion-inhibitory antibodies inhibit proteolytic processing of apical membrane antigen 1 of Plasmodium falciparum merozoites. Proc Natl Acad Sci USA 2003, 100:12295-12300.

24. Narum DL, Haynes JD, Fuhrmann S, Moch K, Liang H, Hoffman SL, Sim BK: Antibodies against the Plasmodium falciparum receptor binding domain of EBA-175 block invasion pathways that do not involve sialic acids. Infect Immun 2000, 68:1964-1966.

25. Blackman MJ, Scott-Finnigan TJ, Shai S, Holder AA: Antibodies inhibit the protease-mediated processing of a malaria merozoite surface protein. J Exp Med 1994, 180:389-393.

26. Sim BK, Orlandi PA, Haynes JD, Klotz FW, Carter JM, Camus D, Zegans ME, Chulay JD: Primary structure of the $175 \mathrm{~K}$ Plasmodium falciparum erythrocyte binding antigen and identification of a peptide which elicits antibodies that inhibit malaria merozoite invasion. $J$ Cell Biol 1990, 111:1877-1884.

27. Blackman MJ, Heidrich HG, Donachie S, McBride JS, Holder AA: A single fragment of a malaria merozoite surface protein remains on the parasite during red cell invasion and is the target of invasion-inhibiting antibodies. J Exp Med 1990, 172:379-382.

28. Persson KE, McCallum FJ, Reiling L, Lister NA, Stubbs J, Cowman AF, Marsh K, Beeson JG: Variation in use of erythrocyte invasion pathways by Plasmodium falciparum mediates evasion of human inhibitory antibodies. J Clin Invest 2008, 118:342-351.

29. Tebo AE, Kremsner PG, Luty AJ: Plasmodium falciparum: a major role for IgG3 in antibody-dependent monocyte-mediated cellular inhibition of parasite growth in vitro. Exp Parasitol 2001, 98:20-28.

30. Flyg BW, Perlmann H, Perlmann P, Esposito F, Berzins K: Wild isolates of Plasmodium falciparum malaria show decreased sensitivity to in vitro inhibition of parasite growth mediated by autologous host antibodies. Clin Exp Immunol 1997, 107:321-327.

31. Chizzolini C, Trottein F, Bernard FX, Kaufmann MH: Isotypic analysis, antigen specificity, and inhibitory function of maternally transmitted Plasmodium falciparum-specific antibodies in Gabonese newborns. Am J Trop Med Hyg 1991, 45:57-64. 
32. Marsh K, Otoo L, Hayes RJ, Carson DC, Greenwood BM: Antibodies to blood stage antigens of Plasmodium falciparum in rural Gambians and their relation to protection against infection. Trans $R$ Soc Trop Med Hyg 1989, 83:293-303

33. Brown J, Greenwood BM: Cellular and humoral inhibition of Plasmodium falciparum growth in vitro and recovery from acute malaria. Parasite Immunol 1985, 7:265-275.

34. Brown GV, Anders RF, Knowles G: Differential effect of immunoglobulin on the in vitro growth of several isolates of Plasmodium falciparum. Infect Immun 1983, 39:1228-1235.

35. Brown GV, Anders RF, Mitchell GF, Heywood PF: Target antigens of purified human immunoglobulins which inhibit growth of Plasmodium falciparum in vitro. Nature 1982, 297:591-593.

36. Dent A, Malhotra I, Mungai P, Muchiri E, Crabb BS, Kazura JW, King CL: Prenatal malaria immune experience affects acquisition of Plasmodium falciparum merozoite surface protein-1 invasion inhibitory antibodies during infancy. J Immunol 2006, 177:7139-7145

37. John CC, O'Donnell RA, Sumba PO, Moormann AM, de Koning-Ward TF, King CL, Kazura JW, Crabb BS: Evidence that invasion-inhibitory antibodies specific for the 19-kDa fragment of merozoite surface protein-1 (MSP-1 19) can play a protective role against blood-stage Plasmodium falciparum infection in individuals in a malaria endemic area of Africa. J Immunol 2004, 173:666-672.

38. Corran PH, O'Donnell RA, Todd J, Uthaipibull C, Holder AA, Crabb BS, Riley EM: The fine specificity, but not the invasion inhibitory activity, of 19kilodalton merozoite surface protein 1-specific antibodies is associated with resistance to malarial parasitemia in a cross-sectional survey in The Gambia. Infect Immun 2004, 72:6185-6189.

39. O'Donnell RA, de Koning-Ward TF, Burt RA, Bockarie M, Reeder JC, Cowman AF, Crabb BS: Antibodies against merozoite surface protein (MSP)-1(19) are a major component of the invasion-inhibitory response in individuals immune to malaria. J Exp Med 2001, 193:1403-1412

40. Vande Waa JA, Jensen JB, Akood MA, Bayoumi R: Longitudinal study on the in vitro immune response to Plasmodium falciparum in Sudan. Infect Immun 1984, 45:505-510.

41. O'Meara WP, McKenzie FE, Magill AJ, Forney JR, Permpanich B, Lucas C, Gasser RA Jr, Wongsrichanalai C: Sources of variability in determining malaria parasite density by microscopy. Am J Trop Med Hyg 2005, 73:593-598.

42. O'Meara WP, Barcus M, Wongsrichanalai C, Muth S, Maguire JD, Jordan RG, Prescott WR, McKenzie FE: Reader technique as a source of variability in determining malaria parasite density by microscopy. Malar J 2006, 5:118.

43. Persson KE, Lee CT, Marsh K, Beeson JG: Development and optimization of high-throughput methods to measure Plasmodium falciparumspecific growth inhibitory antibodies. J Clin Microbiol 2006, 44:1665-1673.

44. Makler MT, Hinrichs DJ: Measurement of the lactate dehydrogenase activity of Plasmodium falciparum as an assessment of parasitemia. Am J Trop Med Hyg 1993, 48:205-210.

45. Bergmann-Leitner ES, Duncan EH, Mullen GE, Burge JR, Khan F, Long CA

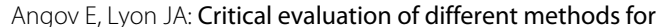
measuring the functional activity of antibodies against malaria blood stage antigens. Am J Trop Med Hyg 2006, 75:437-442.

46. Sanchez BA, Varotti FP, Rodrigues FG, Carvalho LH: Validation of a Plasmodium falciparum parasite transformed with green fluorescent protein for antimalarial drug screening. J Microbiol Methods 2007, 69:518-522

47. Contreras CE, Rivas MA, Dominguez J, Charris J, Palacios M, Bianco NE, Blanca I: Stage-specific activity of potential antimalarial compounds measured in vitro by flow cytometry in comparison to optical microscopy and hypoxanthine uptake. Mem Inst Oswaldo Cruz 2004 99:179-184

48. Shi YP, Udhayakumar $\bigvee$, Oloo AJ, Nahlen BL, Lal AA: Differential effect and interaction of monocytes, hyperimmune sera, and immunoglobulin $\mathrm{G}$ on the growth of asexual stage Plasmodium falciparum parasites. Am J Trop Med Hyg 1999, 60:135-141.

49. Coley AM, Parisi K, Masciantonio R, Hoeck J, Casey JL, Murphy VJ, Harris KS, Batchelor AH, Anders RF, Foley M: The most polymorphic residue on Plasmodium falciparum apical membrane antigen 1 determines binding of an invasion-inhibitory antibody. Infect Immun 2006, 74:2628-2636

50. Coley AM, Campanale NV, Casey JL, Hodder AN, Crewther PE, Anders RF Tilley LM, Foley M: Rapid and precise epitope mapping of monoclonal antibodies against Plasmodium falciparum AMA1 by combined phage display of fragments and random peptides. Protein Eng 2001, 14:691-698.

51. O'Donnell RA, Saul A, Cowman AF, Crabb BS: Functional conservation of the malaria vaccine antigen MSP-119 across distantly related Plasmodium species. Nat Med 2000, 6:91-95.

52. Tonkin CJ, van Dooren GG, Spurck TP, Struck NS, Good RT, Handman E, Cowman AF, McFadden Gl: Localization of organellar proteins in Plasmodium falciparum using a novel set of transfection vectors and a new immunofluorescence fixation method. Mol Biochem Parasitol 2004, 137:13-21.

53. O'Donnell RA, Freitas-Junior LH, Preiser PR, Williamson DH, Duraisingh M, McElwain TF, Scherf A, Cowman AF, Crabb BS: A genetic screen for improved plasmid segregation reveals a role for Rep20 in the interaction of Plasmodium falciparum chromosomes. EMBO J 2002, 21:1231-1239.

54. Cormack BP, Valdivia RH, Falkow S: FACS-optimized mutants of the green fluorescent protein (GFP). Gene 1996, 173:33-38.

55. Wu Y, Sifri CD, Lei HH, Su XZ, Wellems TE: Transfection of Plasmodium falciparum within human red blood cells. Proc Natl Acad Sci USA 1995 92:973-977.

56. Mamoun CB, Gluzman IY, Goyard S, Beverley SM, Goldberg DE: A set of independent selectable markers for transfection of the human malaria parasite Plasmodium falciparum. Proc Natl Acad Sci USA 1999, 96:8716-8720.

57. Crabb BS, Cowman AF: Characterization of promoters and stable transfection by homologous and nonhomologous recombination in Plasmodium falciparum. Proc Natl Acad Sci USA 1996, 93:7289-7294.

58. Fidock DA, Wellems TE: Transformation with human dihydrofolate reductase renders malaria parasites insensitive to WR99210 but does not affect the intrinsic activity of proguanil. Proc Natl Acad Sci USA 1997, 94:10931-10936.

59. Janse CJ, Franke-Fayard B, Waters AP: Selection by flow-sorting of genetically transformed, GFP-expressing blood stages of the rodent malaria parasite, Plasmodium berghei. Nat Prot 2006, 1:614-623.

60. Howard RJ, Battye FL, Mitchell GF: Plasmodium-infected blood cells analyzed and sorted by flow fluorimetry with the deoxyribonucleic acid binding dye 33258 Hoechst. J Histochem Cytochem 1979, 27:803-813

doi: 10.1186/1475-2875-9-152

Cite this article as: Wilson et al., Development of fluorescent Plasmodium falciparum for in vitro growth inhibition assays Malaria Journal 2010, 9:152

\section{Submit your next manuscript to BioMed Central and take full advantage of:}

- Convenient online submission

- Thorough peer review

- No space constraints or color figure charges

- Immediate publication on acceptance

- Inclusion in PubMed, CAS, Scopus and Google Scholar

- Research which is freely available for redistribution
C) Biomed Central 